NASA/TM-2000-209617

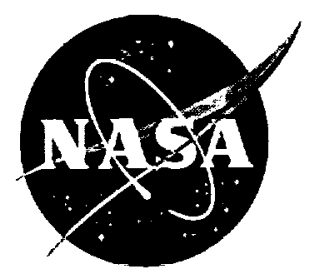

\title{
AWE: Aviation Weather Data Visualization Environment
}

\author{
Lilly Spirkovska, Suresh K. Lodha
}


Since its founding, NASA has been dedicated to the advancement of aeronautics and space science. The NASA Scientific and Technical Information (STI) Program Office plays a key part in helping NASA maintain this important role.

The NASA STI Program Office is operated by Langley Research Center, the Lead Center for NASA's scientific and technical information. The NASA STI Program Office provides access to the NASA STI Database, the largest collection of aeronautical and space science STI in the world. The Program Office is also NASA's institutional mechanism for disseminating the results of its research and development activities. These results are published by NASA in the NASA STI Report Series, which includes the following report types:

- TECHNICAL PUBLICATION. Reports of completed research or a major significant phase of research that present the results of NASA programs and include extensive data or theoretical analysis. Includes compilations of significant scientific and technical data and information deemed to be of continuing reference value. NASA's counterpart of peer-reviewed formal professional papers but has less stringent limitations on manuscript length and extent of graphic presentations.

- TECHNICAL MEMORANDUM. Scientific and technical findings that are preliminary or of specialized interest, e.g., quick release reports, working papers, and bibliographies that contain minimal annotation. Does not contain extensive analysis.

- CONTRACTOR REPORT. Scientific and technical findings by NASA-sponsored contractors and grantees.
- CONFERENCE PUBLICATION. Collected papers from scientific and technical conferences, symposia, seminars, or other meetings sponsored or cosponsored by NASA.

- SPECIAL PUBLICATION. Scientific, technical, or historical information from NASA programs, projects, and missions, often concerned with subjects having substantial public interest.

- TECHNICAL TRANSLATION. Englishlanguage translations of foreign scientific and technical material pertinent to NASA's mission.

Specialized services that complement the STI Program Office's diverse offerings include creating custom thesauri, building customized databases, organizing and publishing research results ... even providing videos.

For more information about the NASA STI

Program Office, see the following:

- Access the NASA STI Program Home Page at http://www.sti.nasa.gov

- E-mail your question via the Internet to help@sti.nasa.gov

- Fax your question to the NASA Access Help Desk at (301) 621-0134

- Telephone the NASA Access Help Desk at (301) 621-0390

- Write to:

NASA Access Help Desk

NASA Center for AeroSpace Information 7121 Standard Drive Hanover, MD 21076-1320 
NASA/TM-2000-209617

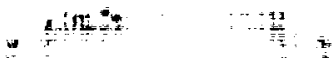

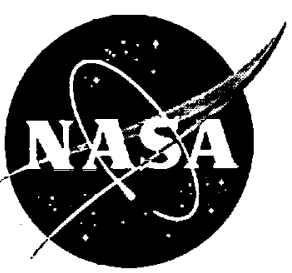

\section{AWE: Aviation Weather Data Visualization Environment}

Lilly Spirkovska

Ames Research Center, Moffett Field, California

Suresh K. Lodha

University of California, Santa Cruz

National Aeronautics and

Space Administration

Ames Research Center

Moffett Field, California 94035-1000 


\section{Acknowledgments}

The authors gratefully acknowledge the suggestions from fellow pilots David Iverson, Cedric Walker, and Butler Hine.

Available from:

NASA Center for AeroSpace Information

7121 Standard Drive

Hanover, MD 21076-1320

(301) 621-0390
National Technical Information Service 5285 Port Royal Road Springfield, VA 22161

(703) $487-4650$ 


\section{AWE: Aviation Weather Data Visualization Environment}

\author{
LILLY SPIRKOVSKA \\ NASA Ames Research Center
}

\author{
SURESH K. LODHA \\ Univ. of California, Santa Cruz
}

\begin{abstract}
The two official sources for aviation weather reports both provide weather information to a pilot in a textual format. A number of systems have recently become available to help pilots with the visualization task by providing much of the data graphically. However, two types of aviation weather data are still not being presented graphically. These are airport-specific current weather reports (known as meteorological observations, or METARs) and forecast weather reports (known as terminal area forecasts, or TAFs). Our system, Aviation Weather Environment (AWE), presents intuitive graphical displays for both METARs and TAFs, as well as winds aloft forecasts. We start with a computer-generated textual aviation weather briefing. We map this briefing onto a cartographic grid specific to the pilot's area of interest. The pilot is able to obtain aviation-specific weather for the entire area or for his specific route. The route, altitude, true airspeed, and proposed departure time can each be modified in AWE. Integral visual display of these three elements of weather reports makes AWE a useful planning tool, as well as a weather briefing tool.
\end{abstract}

\section{Introduction}

Weather is one of the major causes of aviation accidents even though pilots are required to receive an official weather briefing prior to flight. These official weather briefings are textual or verbal and the pilot is responsible for mentally visualizing the provided information. Pilots often turn to unofficial sources for weather, such as television news weather reports, the Weather Channel [ref. $3]$, or a variety of weather web sites [refs. 12, 7, 16, 11, 17], because they offer a graphical presentation of much of the same information. These graphical weather displays allow the pilot to quickly build a better mental model of the big picture of the weather. However, the unofficial sources often provide only a general view of what the weather will be like. The information provided (for example, $40 \%$ chance of rain) is suitable for nonspecialized tasks (such as attending a parade) but not for tasks that require a deeper knowledge of conditions (for example, answering the question Will the clouds be low enough to require flight under instrument flight rules, or can 1 fly under visual flight rules?)
Aviation-specific weather data is too detailed for general public information sources. But because this graphical briefing has been found to be so helpful, more aviationspecific weather information sources have recently been introduced [refs. 4, 12]. They graphically present much of the data available in the official aviation weather briefing. Two pieces of the weather briefing which are not well presented graphically are current weather reports at selected airports of interest and the forecast weather for a subset of those airports. These pieces are presented either only textually or using very simple color-coded symbols which present nothing more than whether the conditions imply visual flight rules, marginal visual flight rules, or instrument flight rules. AWE fills this gap by providing very easy to understand graphics for both airport-specific current weather observations and forecasts. This information is very important for selecting a route, selecting a destination airport, planning for alternate destinations, and selecting an alternate route in case of equipment failure. We also integrate visualization of winds aloft information to help the pilot select the optimal altitude as well as a good route. Winds aloft are already displayed using the well-known directional arrow with barbs representing the wind speed. We present a simpler representation that is quickly and easily interpreted. In the next section, we discuss previous work on visualizing official aviation weather and some related work on aviation specific visualizations. We then describe in more detail our official weather data source available via computer, known as DUATs, and discuss how AWE helps pilots visualize current and forecast weather conditions extracted from DUATs. We conclude with evaluations by pilots, pointing out AWE's advantages and current limitations.

\section{Previous Work}

Official weather briefings can be obtained via telephone, aircraft radio, or infrequently, in person from a Flight Service Station (FSS) specialist ${ }^{1}$ [refs. 8, 9], or via computer from the DUATs (Direct User Access Terminal) system. [ref. 4]. Face-to-face briefings with an FSS specialist have the advantage of access to graphical

1 FSS specialists are Federal Aviation Administration (FAA) employees. 
displays of the data. This advantage is outweighed by the limited availability of FSS facilities. DUATs recently introduced weather graphics to help pilots visualize the "big picture." They provide charts similar to those available through FSS, including surface analysis and surface forecast charts that show the current and forecast location of high/low pressure systems and warm/cold fronts, and areas of precipitation or low-visibility conditions; infrared satellite charts; and charts depicting instrument flight rules (IFR ${ }^{2}$ ) conditions, marginal visual flight rules (MVFR ${ }^{3}$ ) conditions, or visual flight rules $\left(\mathrm{VFR}^{4}\right)$ conditions. An example chart is shown in Figure 1. The charts are very effective in providing a broad (nationwide) overview of the weather, but they do not provide information about specific locations, such as airports along the pilot's route. In particular, DUATs does not provide graphical encodings of three of the most important elements of a weather briefing: airport-specific current weather observations (meteorological observations, or METARs), terminal area forecasts (TAFs), and winds aloft forecasts.

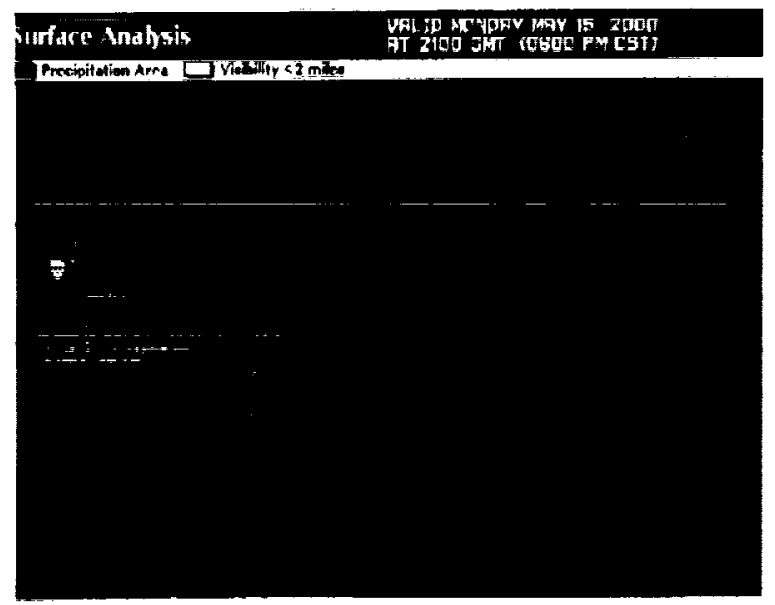

Figure 1: An example of graphics available through DUATs. This surface analysis chart shows low pressure systems ("L"), cold fronts (the blue line across southern California) and warm fronts (the red line from Colorado, through Kansas and Oklahoma), areas of precipitation (such as the rain in Northern California and thunderstorms in eastern Kansas and eastern Oklahoma).

2 IFR = visibility $<3$ miles and/or ceiling $<1,000$ feet.

${ }^{3}$ MVFR $=(3$ miles $<$ visibility $<=5$ miles $)$ and/or $(1,000$ feet $<$ ceiling $<=3,000$ feet $)$.

4 VFR $=$ visibility $>5$ miles and ceiling. $>3,000$ feet.

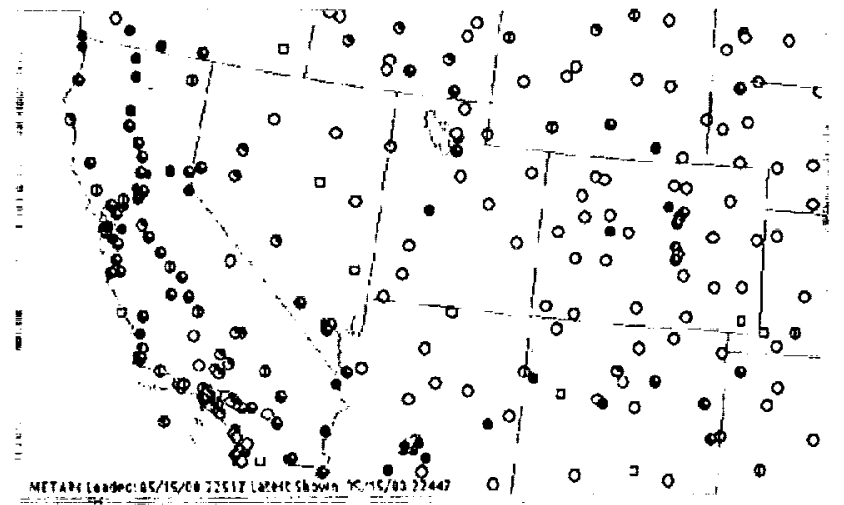

Figure 2: A METAR display available through the National Weather Service web site. Each circle represents a METAR report. The color-coding provides some information on current conditions, such as visual flight rules in effect (green circles) or instrument flight rules in effect (red circle). A circle must be selected with the mouse to extract more information.

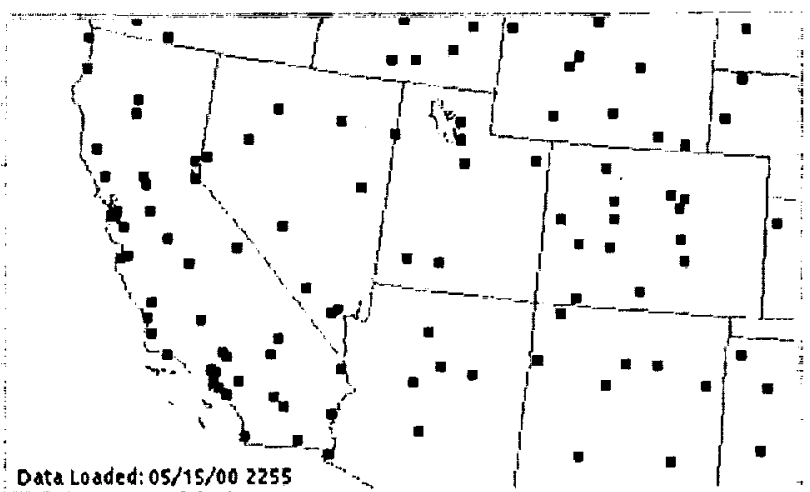

Figure 3: A TAF display available through the National Weather Service web site. Each airport that has a terminal forecast available is represented by a square.

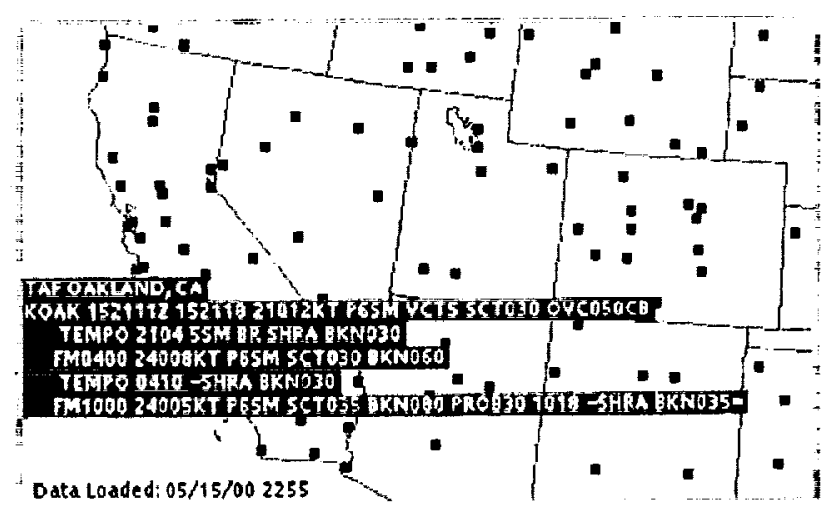

Figure 4: The TAF squares can be selected with the mouse to obtain the full text associated with a NWS TAF display. The TAF is not specific to the pilot's time of arrival at that airport. Rather, all of the information available is shown. The appropriate forecast must be extracted and deciphered by the pilot 
Another recently introduced World Wide Web site for aviation-specific weather graphics is provided by the National Weather Service (NWS) [ref. 12]. Unlike the DUATs site, the NWS site is experimental and unofficial. However, it provides a greater variety of graphics, and allows pilots to zoom in to get more specific information about an area of interest. In addition to the standard charts provided by DUATs, NWS provides charts that graphically encode METARs and TAFs. The encoding is very simplified, however, and does not provide much information beyond whether the weather is IFR, MVFR, or VFR.

Figure 2 shows a METAR display provided by the NWS site. To get information beyond the color codes, the user must select the circle for the airport of interest. The observation data is then displayed textually in the vicinity of the airport, similar to the TAF display in Figure 4. Their handling of TAFs is also elementary. As Figure 3 shows, the NWS TAF display shows only which airports have terminal forecasts available. The user needs to select individual TAF squares to get the associated data. As shown in Figure 4, the data available for that airport is then presented without any filtering based on departure time or another selected time. Though elementary, the DUATs and the NWS graphics systems (as well as the many other similar but non-aviation weather web sites [refs. $3,7,16$ ] are useful as a supplement to official preflight briefings. They provide well-designed graphics for much of the available data. However, neither site fully utilizes the pilot's visual pattern matching skills but still relies a great deal on his cognitive skills in interpreting METARs and TAFs. We focus on what they neglect. AWE presents an intuitive, graphical presentation of these elements and provides an environment that allows the pilot to quickly determine current and forecast conditions along his planned route, determine alternate routes or alternate destinations, and even explore his options with quick "what-if" scenarios. The easy interaction improves the pilot's understanding of current and forecast conditions during the pre-flight briefing.

\section{Related Work}

Before describing AWE and its data source, we discuss two related applications of visualization in the aviation area. First, we begin with the exploratory work of Pruyn and Greenberg [ref. 10]. One of the more difficult procedures is flying an instrument approach in IFR conditions. The pilot must refer to a special approach chart detailing his desired heading and altitude at different positions in the airspace surrounding the airport. Simultaneously, he must fly the airplane, setting power and pitch appropriately for the desired effect. Pruyn and Greenberg applied visualization techniques to help the pilot more easily visualize the approach. Pilots found flying simulated approaches with these enhanced graphics to be easier than using only the standard approach chart. Though their emphasis is not on visualizing weather data, they do consider showing the pilot a simulated wind sock (showing the wind direction and speed, similar to the wind sock at the airport) to give him extra preparation time for when he breaks out of the clouds and is ready to land. Another application of visualization techniques in aviation is the work by Azuma and his colleagues [ref. 1]. One of the latest developments funded by the FAA is for alternative control strategies of aircraft operating under instrument flight rules (such as airline flights). This program is known as Free Flight and will allow pilots to determine their route of flight with minimal coordination with FAA air traffic controllers. Each pilot will bear more of the responsibility for conflict resolution with other flights, leaving FAA air traffic controllers with more opportunity to do strategic planning rather than just immediate control. Azuma's research focuses on providing pilots graphical displays that show them whether a nearby flight's path will converge with their own and on making possible conflicts visually obvious. Free Flight is independent of weather, but they do share an enabling technology known as data link. We discuss data link in more detail below. First we describe AWE and its data source.

\section{Data Source: DUATs}

AWE begins with an official weather briefing as available from the DUATs computer system. DUATs, Direct User Access Terminal system, is offered by private companies under contract to the FAA. It is available to all pilots, from student pilot onward. We used the GTE DUAT system. It obtains its data from the FAA, which in turn obtains some of its data from the National Weather Service. A DUATs area briefing provides:

- Area Forecast including position of fronts, pressure systems, wind conditions, cloud layers, weather (such as rain), and an outlook stating whether conditions will be IFR, MVFR, and VFR

- Severe Weather Warnings

- SIGMETs $^{5}$ and Convective SIGMETs ${ }^{6}$

- AIRMETs $^{7}$ for turbulence, mountain obscuration, widespread IFR conditions, and icing conditions and freezing levels

- Surface Observations (METARs ${ }^{8}$ ) of current conditions, including ceilings, visibility, wind,

5 Significant Meteorological Conditions

6 Example: thunderstorms

7 Airman's Meteorological Information

8 METAR is an acronym for Meteorological Observation 
barometric pressure, temperature and dew points for certain airports

- Pilot Reports

- Radar Summaries that textually provide information about echos, echo movement, and echo intensity

- Terminal Forecasts $\left(\mathrm{TAFs}^{9}\right.$ ) including ceiling, visibility, and wind forecasts for certain airports

- Winds Aloft Forecasts for relevant sites at altitudes of 3,000 feet to 39,000 feet, by 3,000 foot increments

- NOTAMs, or Notices to Airmen, which provide information on such things as airport closures, unlighted obstructions, out-of-service equipment such as runway lights, etc.

As we mentioned previously, DUATS graphics, NWS graphics, and weather graphics available to the general public, such as those shown on television newscasts or the Weather Channel, do a reasonable job of displaying much of the information pilots find useful. Specifically, low/high pressure systems, cold/warm fronts, sequences of satellite images showing clouds and cloud movement, and sequences of radar images showing areas of precipitation are displayed in an easy to understand format. Some of these sources also provide graphics for forecasts for widespread areas of thunderstorms, high wind speeds, or fog. Thus, visualization of most of the textual DUATs briefing is already available.

Rather than duplicating this work, we focus on two elements that are not available graphically: the latest weather reports for selected airports (METARs) and the forecast reports for these airports (TAFs). Although NWS displays winds aloft reports in an easy-to-interpret manner, we explore a simpler display approach but provide additional functionality to help the pilot plan his flight. An example of each of these elements (slightly modified for ease of parsing) is shown in Figure 5, Figure 6, and Figure 7. The integrated visual display of these three elements allows a pilot to more quickly recognize and understand the current and forecast weather in an area of interest and quickly determine his route of flight including altitude.

Winds aloft: The winds aloft report begins with the airport identifier (i.e. KSFO) and then gives the direction the wind is coming from (in tens of degrees), the wind speed, and the temperature at each of the prespecified altitudes. As an example, the original DUATS winds aloft report for KSFO would appear as "KSFO 1112101002 0908-04 ..." which is interpreted as stating that the wind at 3,000 feet (the first element following the airport identifier) is coming from 110 degrees at 12 knots, and the temperature is not specified. Similarly, the wind at 6,000 feet (the second element) is from 100 degrees at 10 knots and the temperature is 2 degrees Celsius.

METAR: The METAR report also begins with the airport identifier. We will decipher the KSQL (San Carlos, CA) airport METAR as an example: "KSQL $181646 Z$ 18014KT 8SM FEW012 SCT050 BKN080 11/08 A3022." "181646Z" specifies the time of observation in the format of day and UTC time, popularly referred to as Zulu time. Thus, "181646Z" represents an observation time of 16:46 Zulu on the 18th of the month. "18014KT" gives the surface winds at the airport and specifies that the wind is coming from 180 degrees at 14 knots. Note that unlike the winds aloft report, the wind direction is specified here as a three digit number. The visibility is " $8 \mathrm{SM}$ " (statute miles). There are no restrictions to visibility. Compare this with the METAR for "KSAC" (shown in Figure 6) where "FG," or fog, is restricting visibility. The cloud layers are specified next. San Carlos has a few clouds at 1,200 feet, scattered clouds at 5,000 feet, and broken clouds at 8,000 feet. The temperature is 11 degrees Celsius and the dew point is 8 degrees. Finally, the barometric pressure is $30.22 \mathrm{inHg}$ (inches of Mercury).

$T A F$ : Interpreting the TAF report is similar to the METAR report. As an example, we will translate part of the KSJC (San Jose, CA) airport TAF: "KSJC $181730 Z$ 181818 00003KT P6SM SCT200 BECMG 2223 32017KT P6SM FEW050 SCT200 FM0900 18020KT 3SM BR BKN020 OVC080" The report time is on the $18 \mathrm{th}$ of the month at 17:30 Zulu. The forecast is valid for the 18 th from $18: 00 \mathrm{Z}$ to the 19 th at $18: 00 \mathrm{Z}$. The weather will be 3 knot winds from 0 degrees, visibility 6 statute miles or greater, with scattered clouds at 20,000 feet. Between 22:00Z and 23:00Z it will become ("BECMG") wind from 320 degrees at 17 knots, plus 6 statute miles visibility, with a few clouds at 5,000 feet and scattered clouds at 20,000 feet. Finally, from 09:00Z (the following day), the wind will be from 180 degrees at 20 knots, the visibility will be 3 statute miles with mist ("BR"), with broken clouds at 2,000 feet and overcast clouds at 8,000 feet. Note that the FAA provides a standard interpretation of the cloud cover amount: FEW means $1 / 8$ of the sky or less is obscured by clouds, SCT means between $1 / 8$ and $3 / 8$ of the sky has clouds, BKN means $4 / 8$ to $7 / 8$ of the sky, and OVC means the entire (8/8) sky has clouds. The FAA also provides a list of standard contractions for visibility obscurations. Our examples are not for comprehensive coverage, but rather for general understanding. Hence, only a few options are discussed.

${ }^{9} \mathrm{TAF}$ is an acronym for Terminal Area Forecast 


\section{AWE Approach}

The Aviation Weather Environment, AWE, provides an environment for the pilot to interact with and obtain the information he needs to effectively plan a flight. AWE is written using $\mathrm{C}++$, OpenGL, and Xforms and runs on an SGI workstation. For in-flight use (as discussed later), it was easily ported to a Sony Superslim Pro Notebook computer running Mandrake Linux. The input to the AWE prototype is a DUATs briefing for a specific area, for example, a 95 nautical mile $(\mathrm{nm})$ radius from the Palo Alto airport, KPAO. We map this briefing onto a grid specific to the pilot's route or his area of interest and only include information relevant to his flight. For instance, for route-specific weather, rather than displaying current data available for his destination, we use forecasts available for his proposed time of arrival (automatically computed from his route and chosen departure time). We use visualization techniques [refs. $2,14,15$ ] such as color coded icons to present the information in the most cognitively easy-to decipher format.

Much underlying capability is required to visualize a DUATs briefing. This includes providing AWE information about airports ${ }^{10}$, parsing the briefing, and translating it into a computer-understandable version. The user's interaction with AWE requires a different set of capabilities. AWE allows the user to specify his flight including route, desired altitude, true airspeed, and proposed departure time; select whether he wants to see current weather or forecast weather; and select whether the area of interest is just airports along the route or all airports in the area. The user is able to modify any of the route parameters and see the effect on weather he might encounter. We discuss each of these issues in the following sections.

\section{AWE Foundation}

The underlying capability, or AWE's foundation, consists of object-oriented programming classes that deal with information about airports, METAR, TAF, and winds aloft. It also includes supporting classes that know how to deal with latitude and longitude coordinates and can find distances between lat/long locations. Four data files are used by AWE. Airport identifiers as well as the latitude and longitude coordinates of the airport are specified in a user readable data file, and the DUATs briefing is translated into three separate files: one containing current METARs, one containing TAF forecasts, and one containing winds aloft forecasts.

The winds aloft forecast is transferred directly with little modification. The class that deals with winds aloft

${ }^{10}$ Locations of navigation aids, like VORs (VHF OmniRange), would also be useful and can easily be added to AWE. contains methods for retrieving the obvious elements. We also provide a method for forecasting the winds aloft at an arbitrary lat/long location. DUATs only provides winds aloft for certain locations and for certain altitudes. Thus we must do two interpolations to compute the appropriate wind. We begin by determining the winds aloft for the pilot-specified altitude at the two closest reporting stations using linear interpolation of the altitudes specified by DUATs. We then use distance-based interpolation, with a slight modification, to determine the winds at the specified latitude/longitude location. Because the winds aloft for a location near a reporting station are likely to be affected much more by conditions at that station than a more distant one, if the arbitrary location is within 30 nautical miles of a station, our forecast is based entirely on the local station winds. Figure 5 shows a sample winds aloft file."

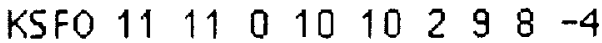
$\begin{array}{lllllllll}7 & 5 & -10 & 27 & 7 & -23 & 25 & 19 & -34\end{array}$ $\begin{array}{lllllllll}24 & 36 & 49 & 24 & 32 & 55 & 25 & 24 & 58\end{array}$ KSAC $\begin{array}{lllllllll}11 & 12 & 0 & 20 & 20 & 1 & 18 & 19 & -5\end{array}$ $\begin{array}{lllllllll}15 & 29 & -10 & 31 & 35 & -24 & 16 & 29 & -35\end{array}$ $\begin{array}{llllllllll}24 & 3.3 & 4.9 & 24 & 31 & 5.5 & 26 & 20 & 58\end{array}$

Figure 5: Sample winds aloft file. The airport identifier is followed by groups of three elements: wind direction, wind speed, and temperature. These groups of three are available for prespecified altitudes from 3,000 feet to 39,000 feet, in 3,000 foot increments

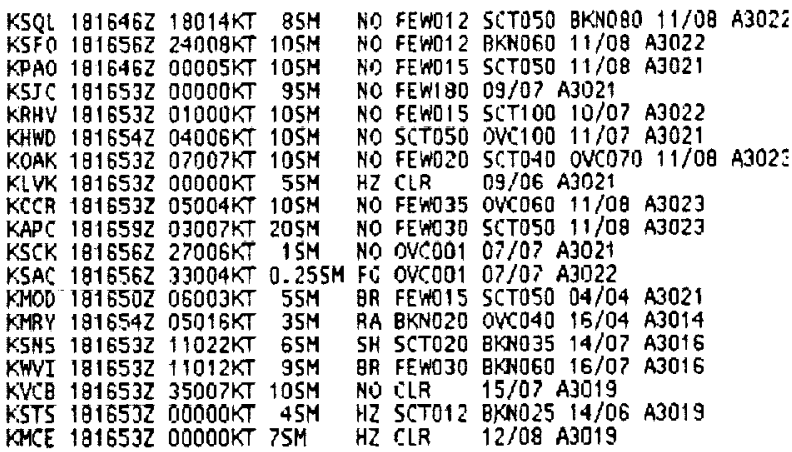

Figure 6: Sample METAR file. Each line represents a METAR for a specific airport, specified by the airport identifier (first element). It also specifies the time of observation, wind direction and wind speed, visibility, visibility restrictions, cloud layers (with coverage amount and altitude), temperature, dew point, and barometric pressure.

11 For ease of parsing, when we translate winds aloft reports for use by AWE, we arbitrarily choose 0 degrees for the first temperature. 
Since our emphasis is on exploring how best to represent information and how to best allow the user to interact with a weather environment system, rather than rigorously parsing DUATs output, the METARs and TAFs are modified from their original format, as shown in Figure 6 and Figure 7.

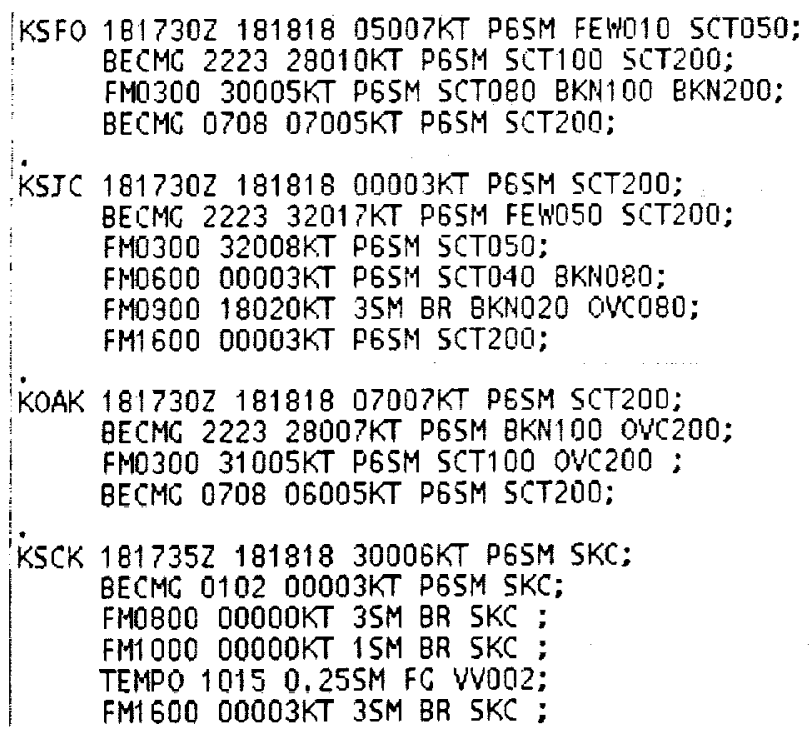

Figure 7: Sample TAF file. A TAF for an aiport extends from the airport identifier to the dot ("."). Each TAF provides the time the forecast was created followed by the effective times of each forecast element. Each element specifies the wind direction and speed, visibility and restrictions to visibility, and cloud layers (with coverage amount and altitude).

For instance, we always associate an obstruction to visibility. If none was given in the DUATs briefing, we insert "NO." Also, we delete the input format comments and extra notations associated with METARs and insert semi-colons into TAFs so we can simplify our parser.

The two final foundation classes are Awe_interface and Awe. Awe_interface deals with interactions with the user, properly updating the input forms. The Awe class maintains a list of known airports, and reads and updates winds aloft, METAR, and TAF reports. It also provides various search methods, such as finding the closest airport to an arbitrary latitude/longitude position; getting the METARTAF for an airport with reporting capability; getting a representative METAR/TAF for non-reporting airports; finding the closest and second closest winds aloft forecasts; or keeping track of the user's chosen route. Each of these methods is used by other foundation classes to help provide what the user wants.

\section{Graphical Interface and Display}

The graphics portion of AWE relies on the foundation classes to compute what information to display. We will now discuss how we display it. We begin by texturing the background AWE window with our local area of the San Francisco Sectional Aeronautical chart. The chart shows the location of airports, navigation aids, controlled and special use airspace, obstructions, natural terrain features (such as water and hills, depicted using color coded altitudes), and congested areas (such as cities, depicted in yellow). Although it may look cluttered and complex, the chart background texture gives pilots a familiar environment with which to interact and provides them with additional information for making their "go/no-go" decision. For example, a 2,000 foot ceiling presents a different situation if the airport is in a flat region versus a narrow valley surrounded by tall mountains. Overlaying the weather on the chart consolidates the weather and the terrain surrounding the airport allowing the pilot to make a decision by looking only at one source.

\section{Defining the Flight}

The pilot specifies his route of flight by selecting (with the mouse) a sequence of airports ${ }^{12}$ The user is able to extend his route by adding an airport to the end, modify his route by deleting airports off the end until the modification point is reached (eventually backtracking to the beginning if desired), or specify a new route. As airports are added or deleted, the interface is updated to reflect the current specified route. The background screen with a route selected by the pilot is shown in Figure 8 .

Using sliders, the pilot is able to select his flight altitude and the aircraft's true airspeed. The pilot is also given an input window in which to specify his proposed departure time. These selections are used to determine what specific information to display, as discussed below.

12 As stated earlier, AWE does not currently recognize navigation aids such as VORs. 


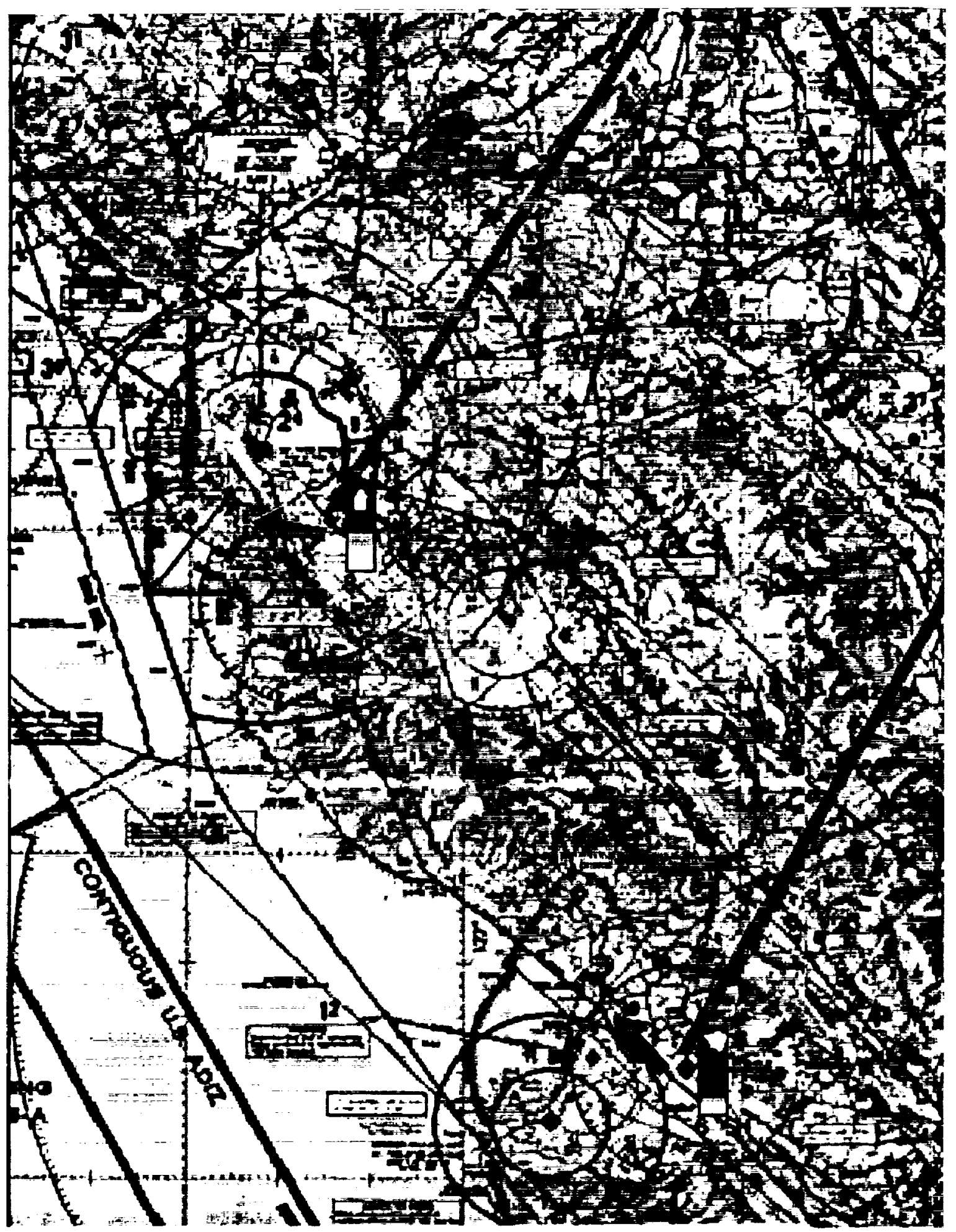

Figure 8: Route METARs and winds aloft shown alongside a pilot-selected route. A pin arrow graphically depicts the wind direction. The number alongside the arrow represents the wind speed. The route is specified by clicking on the airport symbols and is shown by the dark blue line. The METARs are shown in symbolic form (the vertical rectangle) and textual form. The textual form provides all the elements available in the DUATS METAR. The symbolic form shows the more important information graphically, employing the pilot's pattern recognition abilities more than his cognitive abilities. The top portion shows the wind direction and speed (the direction is shown by the direction of the arrow, while the speed is shown by the thickness of the arrow). The bottom portion is subdivided into the cloud layers. The cloud coverage amount is color-coded with lighter colors equating with less coverage. Thus, clear sky conditions are shown as white, whereas overcast sky conditions are shown as very dark gray. The lighter colors pose no problems even to VFR only pilots. The darker colors may signal adverse conditions that need to be examined further. 


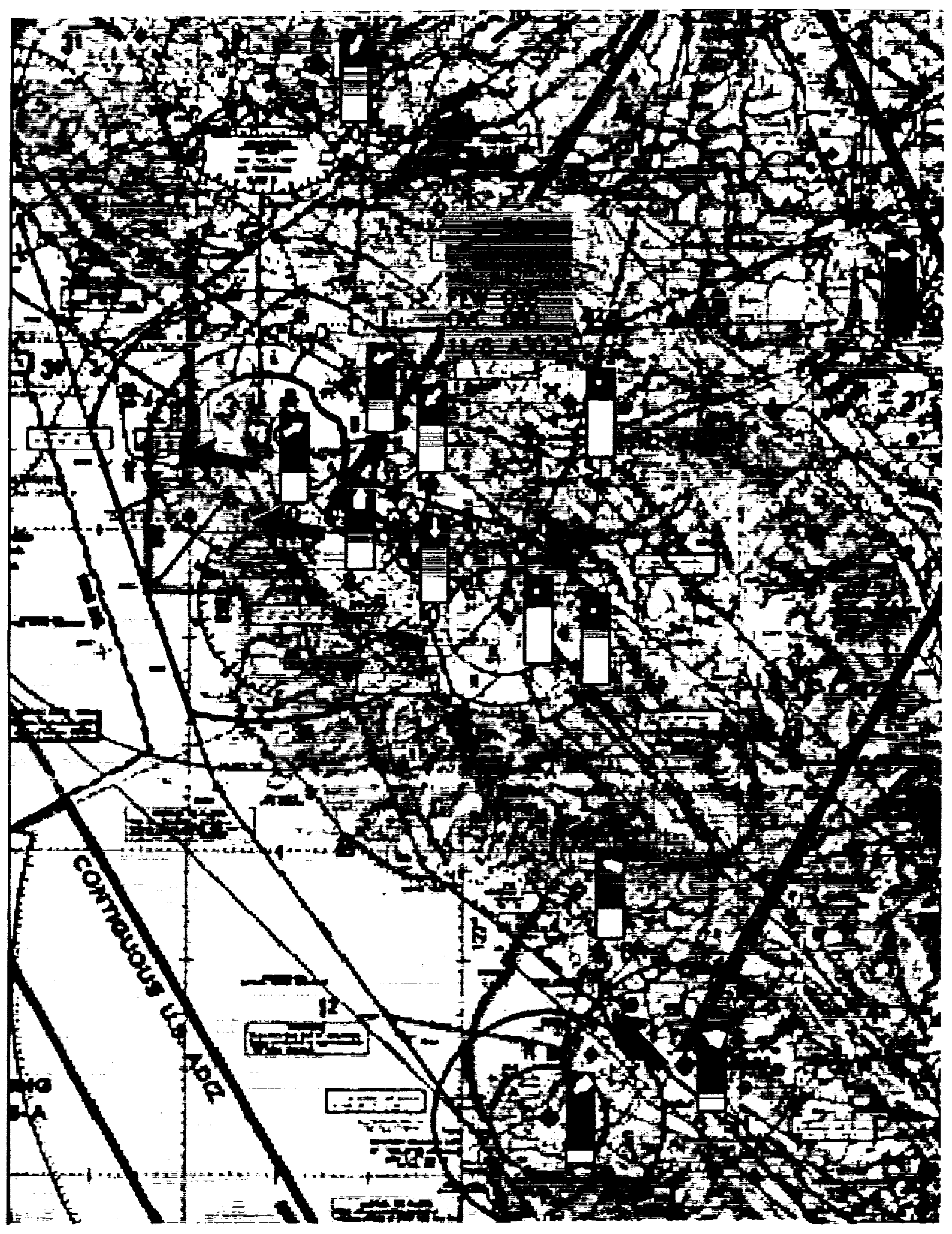

Figure 9: Area METARs. All the METAR reports available for the charted area. METARs can be shown in symbolic or textual format, as shown here. They can also be shown in iconic format, as described in the text. The interpretation of the symbols is exactly as in the previous figure. 


\section{Selecting Information Overlays}

AWE provides the pilot with a number of options in selecting what information to overlay. These include:

- Display focus: display area wide weather vs. routespecific weather;

- Type of weather: display current weather observations (METAR) or forecast weather (TAF), and/or winds aloft;

- Display formats: display a symbolic representation, an iconic representation, or a textual representation of either METARs or TAFs;

- Report locality: display only weather for airports with reporting capability or also display closest available weather for airports without reporting capability.

We describe each of these options below.

Display Focus: The pilot can choose to display weather at airports either just along his route of flight, as shown in Figure 8, or at airports in the entire area known by AWE, as shown in Figure 9. The area-wide weather option is especially useful during the planning phase. The pilot can view all available weather and then choose a route of flight. Conversely, if he has already chosen a destination, route-specific weather shows him only information relevant to his flight.

Type of Weather: The pilot can choose to view either current (METAR) or forecast (TAF) weather, as well as winds aloft information. Most (probably all) airports that provide TAF forecasts also provide METAR observations. Therefore, we implemented the options to display METARs or to display TAFs to be mutually exclusive to avoid screen clutter; that is, either METARs or TAFs can be displayed, but not both simultaneously. Winds aloft, on the other hand, provide complementary information to both sources and can be displayed either alone or with a TAF or METAR. METARs and TAFs provide surface winds associated with the reporting airport. Winds aloft reports provide winds at various altitudes and are associated with a much wider area around the airport.
Report locality: Not all airports AWE knows about have weather reporting capabilities. If the pilot is viewing route-specific weather, we provide him with the option of choosing to display the nearest report (METAR or TAF) for airports that fit this criteria. To accomplish this, the pilot chooses the "show closest available weather" option.

Time-dependent Information: Pilots need the forecast weather at the time of arrival at each en-route checkpoint (airport, in AWE), not the forecast for the departure time. To eliminate the need for the pilot to specify a full flight plan with expected arrival times, we calculate arrival times automatically based on the specified true airspeed and departure time. If the pilot is looking at route-specific TAFs, he will be given the appropriate forecast based on this information.

Choosing an Appropriate Forecast: Determining the appropriate forecast is not as simple for a computer as it is for a person. DUATs forecasts are not specified as mutually exclusive time ranges. Rather, as illustrated in Figure 7, the general forecast (given first) covers a 24 hour period. Forecasts for more specific times are then given. Even these specific time periods can overlap. As in the KSCK (Stockton airport) TAF of Figure 7, we see that three forecasts apply for 10:30. First, the general one that spans the range 18:00 on the 18 th of the month to $18: 00$ on the 19 th states that the weather will be \{wind 300@6, visibility 6 statute miles (sm) or better, sky clear . Then, the "FM1000", states that from 10:00, the weather will be (wind calm, visibility of 1 statute miles with mist, sky clear\}. Finally, the "TEMPO 1015" states that there will be a temporary condition from 10:00 to $15: 00$ of weather [visibility $1 / 4$ statute miles with fog, and a vertical visibility of 200 feet $\}$. AWE must determine which one of these to present to the user. AWE chooses to present the worst scenario. Thus, in this case, it chooses the temporary condition as the representative weather.

\section{Displaying Information Overlays}

We now turn to the display formats.

Winds Aloft Display: Displaying wind information is straightforward. We rotate the wind arrow to show the direction of the wind at that location and display the wind speed alongside. This is simpler than the FSS and NWS method of displaying winds by attaching barbs to the rotated wind arrow. Each barb represents either 5 knots or 10 knots, depending on its length. Our method emphasizes the wind direction over the wind speed. We also find it's easier to quickly read a number (the wind speed) rather than count barbs and try to determine whether it's a short barb or a long one. previously. All three options provide a different perspective and are useful in different situations. Details of the representations are presented below. 
If the pilot has requested area-wide weather, AWE displays all known winds aloft forecasts for central California. If the pilot requests route weather, on the other hand, we display wind information alongside each airport along his route, interpolated as described above and illustrated in Figure 8 by the pink arrows. In this case, the winds aloft are given only for KSFO (the selected route airport in the middle left side of the chart) and KSAC (the selected route airport at the top of the chart). The winds displayed for the other two airports (KMOD (middle right side of chart) and KSNS (bottom of chart)) are computed by AWE. Displaying winds aloft graphically allows the user to quickly compare his flight path to the path of the wind and determine whether to expect a tailwind, headwind, or crosswind. It helps his situational awareness by giving him a direct picture of expected conditions. He can then compensate for a crosswind without much thought, or expect to go slower and use more fuel for a strong headwind. Because winds aloft are altitude dependent, the pilot can modify his selected altitude to determine where the winds are most favorable. The display is updated in real time to reflect his selection.

Symbolic METAR/TAF Display: Determining how to display a METAR or a TAF to make it easily decipherable yet provide all the necessary information is more complicated. The FAA approach, used with charts available at Flight Service Stations, are very informative, yet very cryptic. Their symbols, shown in Figure 10, require a lot of memorization and can be easily forgotten if not used regularly. Instead, we could choose to follow the Weather Channel approach and display only a small set of symbols. One disadvantage of this approach is that much of the available information is not represented.

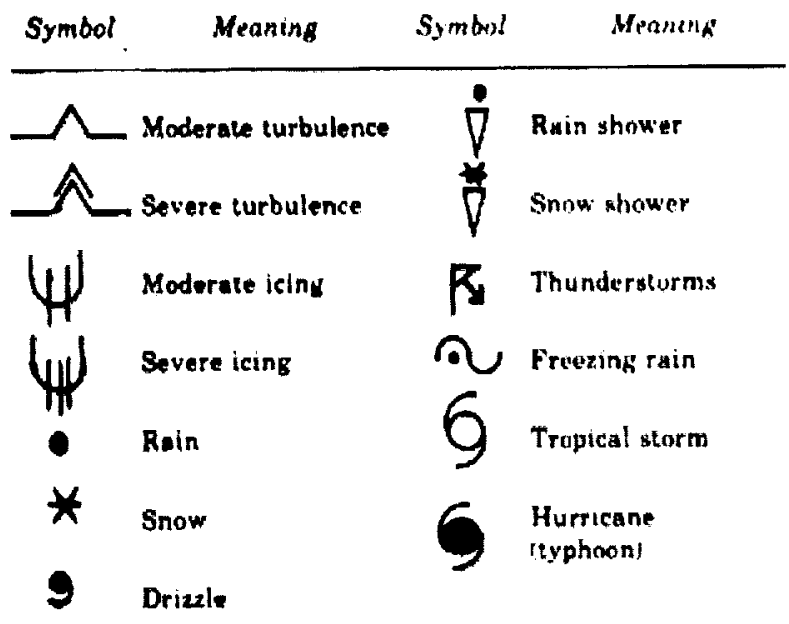

Figure 10: FAA weather symbols and their associated meanings. These symbols are used on charts available at Flight Service Stations, and more recently on DUATs and NWS charts available on the web.
We chose to provide the pilot with all the information available but also to give him the option to only view part of it. As mentioned previously, the pilot has the option to ask for all information textually attached next to the airport, ask for only an iconic view that provides him with a "feel" for the weather, but no specifics, or ask for a symbolic view which provides him with an overview of the weather in a very easy to interpret format. The standard display uses the symbolic representation as shown in Figure 8.

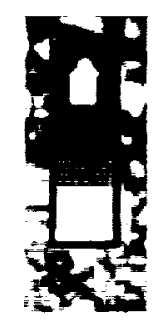

Figure 11: Close-up view of a symbolic representation of a METAR. The blue rectangle at the top represents the wind direction and speed. The direction is shown by the direction of the arrow. In this case the wind is coming from the South. The speed is shown by the thickness of the arrow's base. In this case, it's fairly windy (in the range of 16 knots). The gray part of the rectangle shows the cloud layers. Cloud coverage amounts are color coded, with lighter colors representing less coverage. Hence, white represents clear conditions, very light gray corresponds to few clouds, light gray to scattered clouds, medium gray to broken clouds, and dark gray to overcast cloud coverage. The gray rectangle shows the sky conditions from 0 to 12,000 feet. The cloud altitude is represented by the fraction of the rectangle colored by the associated gray color. In this case, we see few or no clouds up to about 6,000 feet, a scattered layer from 6,000 feet, and a broken layer above 8,000 feet. The upper altitude of the cloud coverage is not provided by METARs and thus cannot be shown. The cloud rectangle border is black in this case signifying VFR conditions. It would be colored yellow for MVFR and red for IFR conditions. Text below the symbol provides visibility and any restrictions to visibility (none in this case).

Figure 11 shows a close-up view of the symbol for KSQL airport. Each symbol is packed with information. The box at the top displays the surface winds. An obvious glyph to use for aviation applications that allows the coding of both wind direction and wind speed is a wind sock. Every airport has one and pilots are able to interpret them readily. The direction is displayed by the orientation of the wind sock and the speed is displayed by the amount the wind sock is straightened to the 90 degree orientation (with respect to the pole holding it up). We attempted to use a 
wind sock to display wind information as suggested by Pruyn and Greenberg [ref. 10] but found the 3D wind sock did not merge well with the overhead perspective of our 2D view. Also, one of the advantages of displaying the wind direction is diminished when using the wind sock: when using a wind arrow, the pilot can easily compare the wind direction with the orientation of the runways as displayed on the sectional chart (AWE's background image). Thus, crosswind landing conditions become visually obvious. The $3 \mathrm{D}$ wind sock requires more analysis to extract similar information. Therefore, our surface winds display follows a similar model to winds aloft with one modification. Winds aloft all use the same size arrow; the wind speed is presented textually adjacent to the arrow. In contrast, the width of the surface wind arrow varies with the speed of the wind. Light winds (that is, low wind speeds) are represented by thin arrows, whereas strong winds are represented by thick arrows.

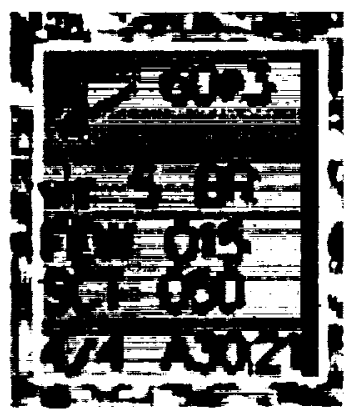

Figure 12: Close-up view of a textual representation of a METAR. The wind direction is shown by the arrow. The wind direction and wind speed are also shown by the text in the upper right corner. In this case, the wind is coming from 60 degrees at 3 knots. The visibility is 5 miles with ' $B R^{\prime}$ ' or mist. Cloud layers are given as a few clouds at 1500 feet and scattered clouds at 5,000 feet. Finally the temperature / dew point are both 4 degrees and the barometric pressure is $30.21 \mathrm{inHg}$. The colored rectangle (yellow) represents marginal VFR (MVFR) conditions. It would be colored red for IFR conditions or gray for VFR conditions.

Compare the winds at KSNS ( 22 knots) shown in Figure 13 and KMOD ( 3 knots) shown in Figure 14. Also notice the winds at KLVK shown in Figure 15. The wind vector at KLVK is 0 degrees at 0 knots, or calm. Calm winds are represented with just a dot since no direction is associated with them. Finally, the border of the wind square is color coded. A red border signifies strong winds ( $>=20 \mathrm{knots}$ ), an orange/yellow border signifies medium winds ( $>=15 \mathrm{knots}$ ), and no border signifies winds below 15 knots.

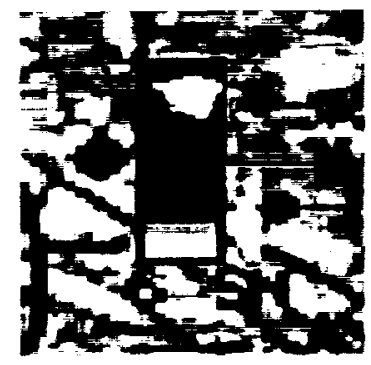

Figure 13: Close-up view of the KSNS METAR symbol

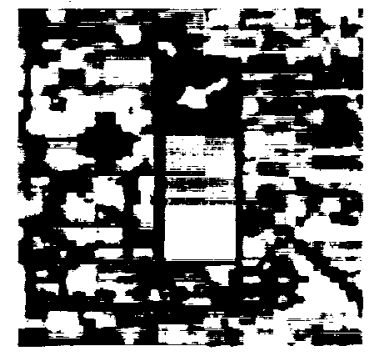

Figure 14: Close-up view of the KMOD METAR symbol

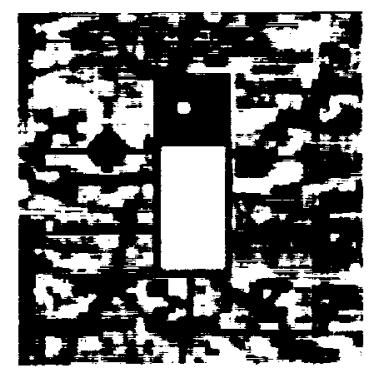

Figure 15: Close-up view of the KLVK METAR symbol.\}

The next element of the METAR/TAF symbol is a rectangle that presents the cloud layers. The rectangle represents the sky from 0 to 12,000 feet $^{13}$. We then pseudo-color the rectangle to show the cloud layers [refs. 6, 13]. As suggested by Bertin [ref. 2] and Tufte [ref. 14] we chose a gray scale to represent the cloud amounts so pilots do not need to remember a color key. Darker colors represent thicker coverage. Hence, white represents a clear sky. Very light gray represents a few clouds, a darker light gray represents scattered clouds, medium gray represents broken clouds, and finally, very dark (nearly black) gray represents an overcast sky. Ceilings (defined as broken or overcast layers) are thus quickly recognized by scanning for darker grays. The border of the rectangle is also color coded to instantly show whether the cloud and visibility conditions are

13 We chose 12,000 feet because automated weather observation systems (AWOS) use the same height threshold for reporting clouds 
IFR (red border), MVFR (orange/yellow border), or VFR (black/no border).

The final element of a METARTAF symbol is text specifying the visibility and obstructions to visibility. That information is presented in black and blends in more with the background than the rest of the symbol. In this way, the information is there if it is needed, but it is not overwhelming.

The METAR/TAF symbols do not represent the temperature, dew point, or barometric pressure values. Also, the values for cloud altitudes are shown only indirectly (by the amount of rectangle filled). If any of those values are desired, the symbol can be transformed into a text box containing all available information as discussed in the next section.

Textual METAR/TAF Display: A textual display of METAR information is shown in Figure 12. To make the task of recognizing crosswind conditions quicker, we still represent the wind direction graphically as well as textually. Unlike the symbolic representation, however, we use only a single width arrow and also provide the details textually.

The textual displays are supplemented with color-coded borders to warn the pilot of possible adverse conditions. Recall that IFR, Instrument Flight Rules, apply when the visibility is $<=3$ miles or the ceiling ${ }^{14}$ is $<=1,000$ feet. Many pilots are prevented either legally (by not having appropriate certification) or practically (by not being proficient) from landing at airports with IFR conditions. MVFR conditions are only a practical, not a legal, deterrent (many pilots feel less safe in marginal conditions). AWE displays airports with IFR conditions with a red border, airports with MVFR conditions with a yellow border, and those with VFR conditions without a border.

Iconic METARTAF Display: There are four primary elements that affect a pilot's "go/no-go" decision: wind conditions, visibility, cloud altitude, and temperature / dew point spread. The first three elements are encoded by our METAR/TAF symbols. The last of these elements (temperature/dew point spread) is only available in METARs. Although our METAR symbol does not encode them, temperature and dew point can be important in certain conditions. For instance, in the San Francisco bay area, morning and evening fog is often a consideration. The temperature / dew point spread then becomes valuable information. If the airport is currently experiencing fog, the spread gives information on when it may clear (especially if you have the previous hour's

${ }^{14}$ Ceiling is defined as a broken (BKN) or overcast (OVC) layer.
METAR and can see a trend in how the spread is changing). Similarly, in the heat of the summer, temperature is very important at high altitude airports since it has a direct effect on aircraft flight characteristics. On the other hand, low temperatures have an effect on starting the engine and they can contribute to possible ice on the airframe. Usually, though, temperatures can be safely classified as noncritical information and are not represented in the iconic format; only the temperature / dew point spread is represented.

Our icons are designed to present a quick overview of all four primary elements. They also give a more abstract summary of the weather than provided by the METAR/TAF symbols. The icon is a triangle (modeled after warning triangles) that is subdivided into four triangles, each representing one of the important elements. The wind triangle (at the top) is shown in white if the wind speed is less than 15 knots (kts), yellow if it's between $15 \mathrm{kts}$ and $20 \mathrm{kts}$, and red if it exceeds $20 \mathrm{kts}$. The visibility triangle (lower left) is shown in white if the visibility is greater than 5 nautical miles, yellow if it is between 3 and 5 nautical miles, and red if it is less than or equal to 3 nautical miles. The cloud altitude triangle (lower right) is shown in white if the lowest ceiling layer is greater than 3,000 feet, yellow if it's above 1,000 and below 3,000 feet, and red if it's at or below 1,000 feet. Finally, the temperature / dew point spread triangle (center) is shown in white if the spread is greater than 4.5 degrees Celsius, yellow if it's between 2 and 4.5 degrees, and red if it's below 2 degrees. Because TAFs do not provide temperature or dew point forecasts, the TAF icon consists of just three triangles. The (center) temperature $/$ dew point spread triangle is always shown in gray. In each of these cases, the color coding serves only to alert the pilot of possible adverse conditions. The thresholds were chosen to coincide with the FAA definitions of IFR and MVFR conditions for visibility and ceiling. The wind speeds and temperature dew point spreads were chosen based on a typical pilot and weather profile. An example area-wide TAF display using icons is shown in Figure 16. 


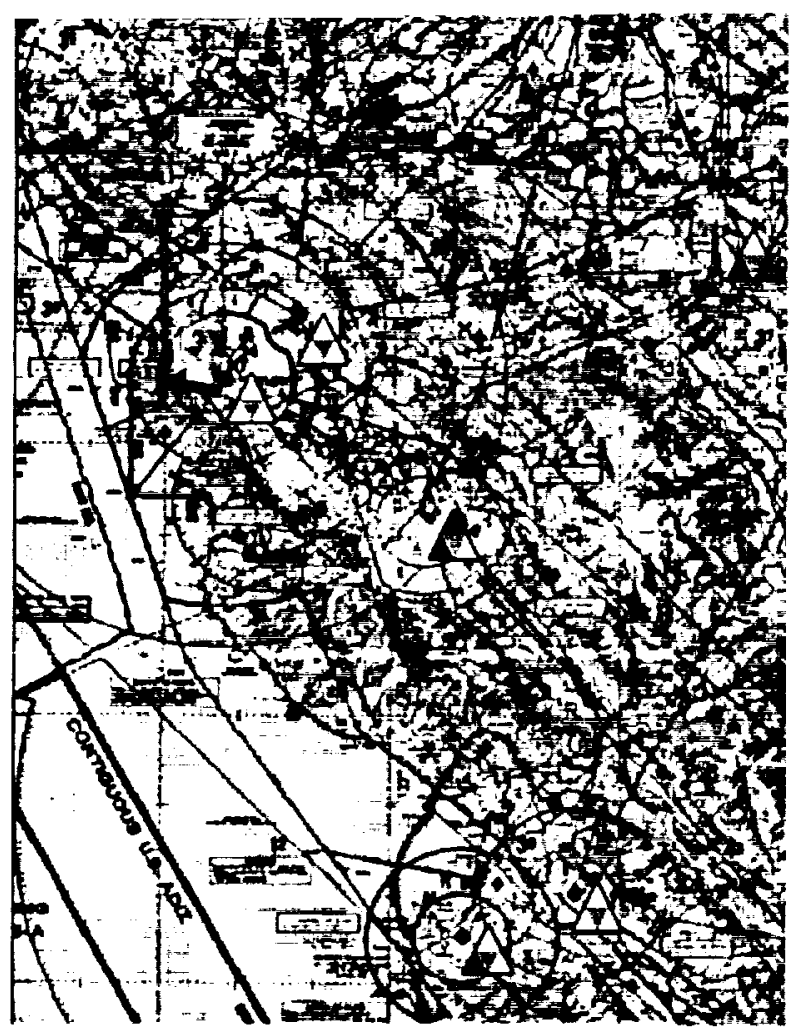

Figure 16: Area TAF display using icons. Each of the TAFs available for the charted area are shown using these triangular icons. Each sub-triangle represents a different element of the TAF. The top triangle portrays the wind conditions, the left bottom triangle portrays the visibility conditions, and the right bottom triangle portrays the cloud layers. Each sub-triangle is color coded to signify VFR (white), MVFR (yellow), and IFR (red) conditions. The wind triangle uses similar colors but represents light winds, medium speed winds, and excessive winds.

\section{Benefits of AWE}

AWE was evaluated by one instrument-rated pilot and two VFR-only pilots, in addition to one of the authors, who is an instrument-rated commercial pilot. All the pilots found AWE to be a very useful tool for examining weather conditions.

AWE's benefits revolve around providing only relevant information in an easy-to-interpret format that supplements the pilot's cognitive abilities with his pattern matching capabilities. With AWE's symbolic format, detecting areas of good weather conditions is reduced to looking for regions of white or light gray cloud bars and gray borders. Similarly, regions of adverse conditions are detected by looking for darker gray cloud bars or red, yellow, or coral borders. The iconic format provides a quick summary of the current or expected conditions. In a glance, pilots can quickly deduce whether there may be potentially adverse conditions. Finally, using the textual display option, a pilot can drill down and get all the available details.

One of the other useful aspects of AWE is its use as a planning tool. Selecting a departure time that offers the best conditions yet fits a pilot's previous commitments is greatly simplified by AWE's automatic selection of the appropriate forecast based on the departure time. Selecting a route or determining possible alternate routes in cases of incorrect forecasts are also simplified with the interactivity provided by the true airspeed and altitude sliders. He can decide to climb to a more favorable altitude, slow down and exploit tailwinds while saving fuel, or depart earlier or later depending on the forecast. He can examine all his options almost instantaneously. If he is flying for pleasure, he can even choose to fly south rather than north if the weather is more favorable in that direction. Extracting similar information from DUATs (either textually or graphically) or from the NWS site, though possible, is much more time consuming.

One of the evaluators pointed out that in addition to AWE's features simplifying the formation of a mental model in the pilot's local area, they vastly improve his ability to form mental models in an unfamiliar area. Pilots know the identifiers for most, if not all, the airports within 100 miles of their home airport. They can immediately picture where a given airport is, how far away it is, and where their flight path will pass in relation to it. If a TAF is not available for their destination airport, they know which airport is closest and which may provide useful data on expected conditions. Non-local pilots, on the other hand, have a more difficult time interpreting a DUATs area briefing. They must refer to the chart or other reference material to determine which airport an identifier refers to, to visualize where airports are located, to determine which airport is closest to one without a TAF, and to visualize what the terrain surrounding the airport looks like. All that information is directly available on AWE. They can now visualize the weather as easily in a distant area as they can in their local area.

A final observation was that AWE is useful not just for pre-flight briefings but also for in-flight weather updates. Because one of the leading causes for loss of control for general aviation flights is continued flight into worsening weather conditions, the prudent pilot gets in-flight weather updates to verify his pre-flight briefing. The only resource currently available for inflight briefings is (aviation) radio contact with FSS specialists and hence all briefings are verbal. Because of frequency congestion and required flying tasks, these briefings tend to be brief and provide only very specific 
information. The pilot is unable to contemplate his options at length.

The Federal Aviation Administration (FAA), National Aeronautics and Space Administration (NASA), and aviation industry are currently developing data link technology which promises to bring much needed data directly to the in-flight pilot. [ref. 5] The driving goal for data link is the Free Flight program that will allow pilots to determine their route of flight with minimal coordination with FAA air traffic controllers. Besides traffic data [ref 1], data link can be used to transfer weather data to the pilot or send weather data from onboard sensors to a central location for dissemination (as pilot reports) to other flights in the general area.

Because of bandwidth limitations, data link proponents are considering providing much of the information in a textual format. However, with the duties required by single-pilot operations, this data must be presented in a cognitively easy-to-decipher format if it is to provide optimal help. AWE can provide one solution to this problem with a slight expansion of the feature set and some additional hardware.

We ported AWE to a more practical platform-a laptop computer-as discussed earlier. We are able to access the aircraft's current position by connecting the laptop to a GPS (global position system) unit. AWE can use this real-time position data to automatically scroll the area displayed on the chart. Data transfer from/to the ground is made possible through emerging satellite phone technology. Qualcomm recently demonstrated data transfer using the Globalstar network of satellites. The technology is scheduled for release before year's end. Thus, by connecting a satellite phone to our notebook computer, we can download the DUATs text while in flight anywhere satellite data transfer coverage is available. Using this setup, the pilot can automatically download weather updates (at times pre-programmed during pre-flight preparations) and get an updated display of weather conditions in his en-route and destination areas. Because AWE graphics display the information so only simple visual pattern matching is required, weather updates will not require much head-down timelfootnote/Head-down time is time spent focusing on instruments or data inside the cockpit rather than scanning outside for traffic.) And because the whole process can be automated, the pilot can always have the latest available weather and modify his plans accordingly.

\section{Future AWE Enhancements}

The evaluator-pilots also pointed out additional features that could improve AWE. First, we have hardwired cloud bars to show cloud levels only from 0 to 12,000 feet. The upper limit was chosen to coincide with automated observation system limits and the performance limitations of many general aviation aircraft. Allowing the user to specify this upper bound would make AWE useful to a larger variety of pilots. Similarly, the definition of adverse conditions has been hardwired. For example, wind speeds in excess of 20 knots are shown with a red border in the symbolic or a red triangle on the iconic display. Cloud altitude and coverage amount color codings coincide with the FAA definitions of IFR, MVFR, and VFR. Allowing the user to specify these boundaries could make AWE even more useful for less experienced pilots or to pilots where $20 \mathrm{knot}$ winds are routine.

The second area for additional features involves visualizing two additional elements of DUATs briefings that are currently being displayed only textually: pilot reports and notices to airmen. Pilot reports (PIREPs) provide information similar to METAR observations. Rather than being collected by instruments or air traffic controllers, in-flight observations are collected and reported by pilots. Because forecasts are not always accurate, PIREPs are useful in confirming the forecast or pointing out areas where it was not accurate. They are especially helpful for determining the extent of icing conditions and the top of the cloud layers.

Notices to airmen (NOTAMs) provide a variety of information potentially helpful to a pilot. Some NOTAMs, such as those specifying instrument approach procedure changes, are textual by nature. Others, however, provide information which could more easily be interpreted if presented visually. Some examples of these are NOTAMs for unlighted obstructions near the airport, acrobatic practice areas, active parachute jumping sites, temporarily prohibited areas where the U.S. President is scheduled to be, and areas of possibly reduced GPS reception.

\section{Summary}

AWE presents a new method of interacting with aviation weather. It can be used either as a briefing tool or as a planning tool. We begin with an area briefing from the FAA-approved DUATs aviation briefing service. We then present a subset of the provided information graphically. The subset is selected to augment current techniques for visualizing weather information. The use of satellite images to display clouds, radar echos to display precipitation, and contour lines to display temperatures are well known and quite effective. The display of winds as arrows is also currently used effectively. We concentrate on displaying aviation-specific weather that is not currently displayed effectively. In particular, AWE displays current airport weather observations, known as METARs, and airport weather forecasts, known as TAFs. Although the display of wind direction and speed has been explored previously, AWE also displays winds aloft data because 
we find it integrates well with METARs and TAFs and is very useful to the pilot for planning purposes.

AWE provides the pilot options to display area-wide or route-specific winds aloft, current METAR observations, and TAF forecasts. METARs and TAFs can be displayed either as symbols, higher-level icons, or as a text box. Text boxes present the same information as DUATs (except that we simplified the DUATs briefing to accommodate our parsing routines by discarding comments and extra details). Symbols and icons present a quick, easily interpretable view of weather conditions in general, making adverse conditions visually easy to detect.

AWE provides a simple method of specifying a route. By using the mouse and its three keys, the pilot can add a checkpoint, modify the route by deleting checkpoints off the end (back to the beginning if so desired) and replacing them with other checkpoints, or specify a new route by clearing the previously specified route and adding checkpoints. AWE also allows the pilot to specify his airplane's true airspeed, select an altitude, and select his departure time. Any of these can be modified during his AWE session, turning AWE into a useful planning tool. METARs, TAFs, and/or winds aloft data are updated immediately to reflect the new selections. Thus, the pilot can choose a favorable altitude (e.g., with more tailwinds), choose to slow down and save fuel if the winds will let him arrive within a time window of his choice, or choose to depart earlier or later to use the forecast weather to his advantage. The recreational pilot can even use AWE to decide on a direction for his pleasure flight. The direct visualization of weather can especially benefit pilots flying outside of their local area by helping them see where the airports identified in the weather briefing are located and how far they are from each other.

Rather than just displaying weather information directly, AWE provides some automation of functions typically performed by a pilot. Winds aloft for flight path checkpoints are computed by interpolating the winds at the two nearest reporting stations. These estimates are displayed alongside the checkpoints. Conditions specified by METARs and TAFs are automatically classified as IFR, MVFR, or VFR and displayed so they are easy to recognize. Finally, the pilot is given the option of using the nearest airport with a METAR or TAF as a representative for one of his checkpoints if the checkpoint airport does not provide those services. The combination of these features makes AWE a very useful tool for local and non-local pilots alike.

\section{References}

[1] R.Azuma, H. Neely, M. Daily, and M. Correa. Visualization of conflicts and resolutions in a 'free flight' scenario. Proceedings. of IEEE Visualization, pages 433--436, October 1999.

[2] Bertin, Jacques. Semiology of Graphics: Diagrams, Networks, Maps\}. University of Wisconsin Press, Madison, WI, 1983.

[3] The Weather Channel. World Wide Web. www.weather.com.

[4] GTE DUATS. World Wide Web. wwwl.duats.com.

[5] Horne, Thomas A. Beaming up the weather. AOPA Pilot, pages 97-102, March 2000.

[6] MacDonald, L.W.. Using color effectively in computer graphics. IEEE Computer Graphics and Applications, pages 20-35, July/Aug. 1999.

[7] MIT. World Wide Web. cirrus.mit.edu/ gempak/forecast__maps.html.

[8] U.S. Department of Transportation. Aviation Weather: $A C$ 00-6A. US Government Printing Office, Washington, D.C., 1975.

[9] U.S. Department of Transportation. Aviation Weather Services: AC 00-45C. US Government Printing Office, Washington, D.C., 1985.

[10] Pruyn, P.W. and Greenberg, D. P.. Exploring 3d computer graphics in cockpit avionics. IEEE Computer Graphics and Applications, pages 28--35, May 1993.

[11] Aviation Digital Data Service. World Wide Web. adds.awckc.noaa.gov/projects/adds/index.html.

[12] NOAA National Weather Service. World Wide Web. www.awc-

kc.noaa.gov/awc/aviation_weather_center.html.

[13] Shubin, Falck, and Johansen. Exploring color in interface design. ACM Interactions, pages 36--48, July/Aug. 1996.

[14] Tufte. Edward R.. The Visual Display of Quantitative Information. Graphics Press, Cheshire, CT, 1983.

[15] Tufte. Edward R. Envisioning Information. Graphics Press, Cheshire, CT, 1990.

[16] Aviation Weather. World Wide Web. aviationweather.com.

[17] Whitehouse, K.. Weather without the weatherman. IEEE Computer Graphics and Applications, pages 12--15, March 1996. 
Public reporting burden lor this collection of information is estimated to average 1 hour per response, including the time for reviewing instructions, eearching existing date sources, Panering and

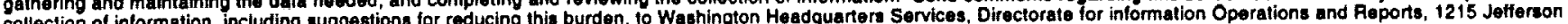
Davis Highway, Suite 1204 Arlington, VA 22202-4302, and to the Oflice of Management and Budget, Paperwork Reduction Project (0704-0188), Washington, DC 20503.

\begin{tabular}{|l|c|c|}
\hline 1. AGENCY USE ONLY (leave blank) & 2. REPORT DATE \\
December 2000 & $\begin{array}{c}\text { 3. REPORT TYPE AND DATES COVERED } \\
\text { Technical Memorandum }\end{array}$
\end{tabular}

4. TITLE AND SUBTITLE 5. FUNDING NUMBERS

AWE: Aviation Weather Data Visualization Environment $505-263-10$

6. AUTHOR(S)

Lilly Spirkovska, Suresh K. Lodha

7. PERFORMING ORGANIZATION NAME(S) AND ADDRESS(ES)

8. PERFORMING ORGANIZATION REPORT NUMBER

A-Xxxxx

Moffett Field, CA 94035-1000 AGENCY REPORT NUMBER

NASA/TM-2000-209617

National Aeronautics and Space Administration

Washington, DC 20546-0001

NASATM-2000-209617

11. SUPPLEMENTARY NOTES

Point of Contact: Lilly Spirkovska, Ames Research Center, MS 269-3, Moffett Field, CA 94035-1000 (650) 604-4234

\section{2a. DISTRIBUTION/AVAILABILITY STATEMENT}

12b. DISTRIBUTION CODE

Unclassified - Unlimited

Subject Category $04 \quad$ Distribution: Standard

Availability: NASA CASI (301) 621-0390

\section{ABSTRACT (MaxImum 200 words)}

The two official sources for aviation weather reports both provide weather information to a pilot in a textual format. A number of systems have recently become available to help pilots with the visualization task by providing much of the data graphically. However, two types of aviation weather data are still not being presented graphically. These are airport-specific current weather reports (known as meteorological observations, or METARs) and forecast weather reports (known as terminal area forecasts, or TAFs). Our system, Aviation Weather Environment (AWE), presents intuitive graphical displays for both METARs and TAFs, as well as winds aloft forecasts. We start with a computergenerated textual aviation weather briefing. We map this briefing onto a cartographic grid specific to the pilot's area of interest. The pilot is able to obtain aviation-specific weather for the entire area or for his specific route. The route, altitude, true airspeed, and proposed departure time can each be modified in AWE. Integral visual display of these three elements of weather reports makes AWE a useful planning tool, as well as a weather briefing tool.

\begin{tabular}{|c|c|c|c|}
\hline \multicolumn{3}{|c|}{$\begin{array}{l}\text { 14. SUBJECT TERMS } \\
\text { aviation weather reports, pilot graphical displays }\end{array}$} & \begin{tabular}{|} 
15. NUMBER OF PAGES \\
20 \\
16. PRICE CODE \\
A03 \\
20. LIMITATION OF ABSTAACT
\end{tabular} \\
\hline $\begin{array}{l}\text { 17. SECURITY CLASSIFICATION } \\
\text { OF REPORT } \\
\text { Unclassified }\end{array}$ & $\begin{array}{l}\text { 18. SECUAITY CLASSIFICATION } \\
\text { OF THIS PAGE } \\
\text { Unclassified }\end{array}$ & $\begin{array}{l}\text { 19. SECUAITY CLASSIFICATION } \\
\text { OF ABSTRACT } \\
\text { Unclassified }\end{array}$ & $\begin{array}{l}\text { 20. LIMITATION OF ABSTAACT } \\
\text { Unclassified }\end{array}$ \\
\hline
\end{tabular}

